\title{
Los homicidios en la prensa vasca (2002-2012): tratamiento informativo y códigos deontológicos ${ }^{1}$
}

\author{
José Ignacio ARMEnTIA VizUETE \\ ignacio.armentia@ehu.es \\ Universidad del País Vasco UPV/EHU \\ Flora MARÍN MURILlO \\ flora.marin@ehu.es \\ Universidad del País Vasco UPV/EHU \\ José María CAminos Marcet \\ josemaria.caminos@ehu.es \\ Universidad del País Vasco UPV/EHU
}

Recibido: 26 de mayo de 2014

Aceptado: 28 de noviembre de 2014

\section{Resumen}

El artículo recoge un análisis de contenido sobre el tratamiento dado por la prensa vasca a los homicidios ocurridos en Euskadi durante el periodo 2002-2012. Se centra en aquellos aspectos que atañen directamente a la presunción de inocencia, la identidad tanto del agresor/a o víctima, así como a la denominación del suceso y sus connotaciones añadidas. El análisis de estas informaciones pretende enfrentar los textos con las recomendaciones éticas que desde los propios medios y las asociaciones profesionales se han generado, mostrando así sus contradicciones y debilidades. En total, se han analizado 44 casos (4 por año) en los diarios de los grupos Vocento (El Correo y El Diario Vasco) y Noticias (Deia, Noticias de Gipuzkoa y Diario Noticias de Álava), y en Gara, El País y El Mundo.

Palabras clave: Homicidios, diarios, análisis de contenido, deontología, presunción de inocencia.

\section{Coverage of Homicides by the Basque Press 2001-2012: News reporting and Journalistic Ethics}

\begin{abstract}
This article presents the results of an analysis of the regional press's coverage of homicides perpetrated in the Basque Country from 2002 through 2012. The main objective of this study was to determine how closely a wide spectrum of Basque newspapers followed their own codes of ethics as well as those of various associations of professional journalists in their reporting of such events during this period. Content analysis of eight regional newspapers' coverage of 44 cases of homicide ( 4 for each year covered by this study) was carried out to ascertain each publication's track record on ethical issues such as respect for the presumption of innocence and the protection of the identities of both victims and the accused and to gain a clearer picture as to the manner in which they described and framed these events. The newspapers chosen for this study were El Correo and El Diario Vasco (published by Vocento), Deia, Noticias de Gipuzkoa and Diario Noticias de Álava (published by Grupo Noticias), Gara, El País and El Mundo.
\end{abstract}

Keywords: Homicides, newspapers, content analysis, ethics, presumption of innocence.

1 Este artículo está basado en un proyecto de Investigación financiado por el Ministerio de Economía y Competividad, titulado "La evolución en el tratamiento de las muertes violentas en la prensa del País Vasco (referencia CSO2010-1985) 


\section{Referencia normalizada}

ARMENTIA VIZUETE, José Ignacio; MARÍN MURILLO, Flora; y CAMINOS MARCET, José María (2015): "Los homicidios en la prensa vasca (2002-2012): tratamiento informativo y códigos deontológicos". Estudios sobre el Mensaje Periodístico. Vol. 21, Núm. 1 (enero-junio), págs.: 53-72. Madrid, Servicio de Publicaciones de la Universidad Complutense.

Sumario: 1. Introducción. 2. Metodología; 2.1. Corpus del estudio; 2.2. Ficha de análisis. 3. La presunción de inocencia. 4. Asesinato/homicidio. 5. La identidad de la víctima o del agresor. 6. El origen de la víctima y el sospechoso. 7. Encuadres visuales: fotografía y crimen. 8. Conclusiones. 9. Referencias bibliográficas. 10. Anexo 1. 11. Anexo 2.

\section{Introducción}

Homicidios y asesinatos han formado parte de los relatos míticos en todas las culturas. Desde el asesinato de Abel a manos de Caín, hasta los terribles crímenes perpetrados por los dioses y héroes clásicos, el hombre ha narrado estos desdichados acontecimientos en busca de respuestas a tan "peculiares comportamientos".

Cuando el asesinato es político, Barthes dice que se está ante una información, si no lo es se trataría de un suceso. Para este autor, el suceso procede de una clasificación de lo inclasificable, es el desecho inorganizado de las noticias informes; su esencia es negativa, sólo empieza a existir allí donde el mundo deja de ser nombrado, [...] es una información monstruosa" (Barthes, 1977: 225).

La cercanía, la rareza, la excepcionalidad, unido a la gravedad del delito acrecientan el interés informativo por los homicidios, donde la presencia de víctimas es clave para su definición. Montse Quesada señala que "de toda la información que tiene cabida en el ámbito de los sucesos, la que hace referencia a hechos violentos recibe por parte de los medios un trato preferente hasta el punto de que es frecuente que aparezca ocupando la portada de los periódicos o abriendo los informativos de radio y televisión" (2007: 46). Como apuntan Schildkraut y Donley, "crime stories have become an intrinsic component of modern media. Studies have shown that stories pertaining to crime can account for up to 50\% of news coverage" (2012: 175).

Autores como Taylor y Sorenson (2002) o Gekoski, Gray y Adler (2012) han investigado precisamente los factores que intervienen en la especial atención dada por los medios a unos homicidios en particular en detrimento de otros, es decir los criterios de noticiabilidad que afectan a este tipo de sucesos.

En el ámbito nacional Herrero (2003), Quesada (2007), Rodríguez (2011) y Marauri, Rodríguez y Cantalapiedra (2011), entre otros, han puesto el acento en la importancia que la comunicación de estos hechos tiene en la construcción social de la inseguridad ciudadana, los estereotipos raciales, o las situaciones de alarma social.

En estas aportaciones se aboga por la necesidad de contar con informadores especializados capaces no sólo de trasmitir con criterio, y sin caer en el morbo y la espectacularidad, los aspectos más relevantes del suceso, sino incluso realizar un trabajo de investigación, esclareciendo y dando respuestas al cómo y porqué de estos actos.

Sin embargo frente a otro tipo de violencia, como la denominada de género o la violencia terrorista, donde la preocupación de la sociedad, instituciones, profesionales de la información, asociaciones de víctimas y otros colectivos han entretejido un círculo de relaciones donde unos y otros han compartido reflexiones que han cristali- 
zado en normas de conducta, códigos, y decálogos para informar con corrección sobre estos temas, los crímenes producto de la violencia "común" no han merecido de momento la misma atención.

Aunque los libros de estilo de los medios, así como los códigos éticos recogen recomendaciones que aluden a las buenas prácticas, asociadas al rigor periodístico y el respeto a la dignidad y privacidad de la persona, la rutina profesional gana la batalla. El riesgo acrecentado en los últimos años por la intensificación de los juicios paralelos a través de la prensa, ha levantado las alarmas tanto en los ámbitos mediáticos como jurídicos. La colisión entre la libertad de expresión y los derechos de la persona a un juicio justo e imparcial, al honor, la intimidad, a su propia imagen y por supuesto a la presunción de inocencia conlleva una mayor carga de responsabilidad por parte del informador, quien debe velar, para que ambos derechos coexistan. Montalbo Abiol, ante esta diatriba se decanta "por una regulación que pueda, si no eliminar de pleno la gestación del juicio paralelo, sí al menos esgrimir un criterio adecuado para su tratamiento". (2012: 124).

Al margen de este debate se impone el trabajo del informador para controlar la relevancia de las fuentes, el uso correcto del léxico, la idoneidad de las imágenes o la pertinencia de publicitar o no la identidad, el origen o la etnia de víctimas o agresores. La presunción de inocencia debe guiar la labor del periodista, así como el uso responsable de conceptos tales como asesino u homicida.

Sin embargo, el misterio en algunos sucesos crea situaciones de suspense que intrigan al público, avivando su atención. La crónica de sucesos no está exenta de daños irreparables ya que a veces la búsqueda de audiencia se ha servido de la frivolización, el amarillismo, la espectacularidad y la falta de rigor. El caso de Dolores Vázquez fue paradigmático en este sentido, su juicio, condena y posterior absolución por la muerte de la joven Rocío Wanninkhof (2000) puso en entredicho el papel de los medios de comunicación y su compromiso ante la sociedad. Para Barata en este suceso se dieron dos circunstancias que combinadas suelen conllevar una vulneración de la presunción de inocencia: "la competencia que se genera entre los periodistas para obtener y publicar el máximo de datos sobre la investigación y la práctica policial de facilitar la identidad de los detenidos" (2003: 50).

La desaparición de Madeleine McCann y el juicio paralelo que fomentaron los medios británicos haciéndose eco de todo tipo de rumores en torno a los padres de la niña, es otro ejemplo a tener en cuenta. Greer y McLaughlin observaron cómo los diarios incurrían en graves contradicciones ya que las mismas cabeceras que difundían rumores contra los McCann llegaban a ofrecer también textos de opinión criticando dicha práctica: "Even within newspapers, stories that reported rumours and allegations against the McCanns were at times countered by columns or editorials that criticized those same rumours and offered support" (2012: 412).

Ante hechos como este se impone un análisis detallado de este tipo de informaciones encaminado a ahondar en sus defectos y carencias, sus aciertos y sus debilidades. Como apunta Suárez Villegas, "la ética periodística asiste a una tensión dialéctica entre los criterios imperantes en su propia comunidad que recalan en la conciencia profesional y las referencias deontológicas, que establecen criterios que contrarrestan 
la inercia de ciertas prácticas profesionales basadas en prejuicios y estereotipos mayoritarios" (2013: 312).

Las hipótesis de partida de este estudio son las siguientes:

1. Durante este periodo la prensa ha vulnerado en ocasiones la presunción de inocencia en sus informaciones.

2. La denominación del suceso en términos legales no siempre se respeta.

3. La identidad del agresor así como su origen son destacados sobre todo cuando estamos ante inmigrantes o etnias minoritarias.

4. El uso de la fotografía para acompañar a estos sucesos ha aumentado en los últimos años.

5. La utilización de la imagen de la víctima o el agresor tiene un tratamiento desigual según los diferentes medios.

6. El respeto a los códigos éticos en las categorías analizadas puede variar dependiendo del grupo mediático.

\section{Metodología}

\subsection{Corpus del estudio}

Para afrontar un análisis de contenido cuantitativo del tratamiento de los homicidios por parte de la prensa vasca durante el periodo 2002-2012 se han dejado al margen los provocados tanto por ETA como por la violencia de género, ya que estos han sido específicamente objeto de otras investigaciones recientes (ver Cuestas, Canel, Gorrionero [eds.], 2012; Mingolarra, Arocena, Martín [eds.], 2012; Armentia et al., 2012, etc.).

De los 137 homicidios que se produjeron en el País Vasco durante los 11 años estudiados, 6 fueron protagonizados por ETA, mientras que otros 31 corresponden a la violencia de género².

De los 100 restantes, dado que no todos ellos tuvieron el mismo eco mediático e incluso en algunos casos estuvieron ausentes de los medios, se han seleccionado los cuatro sucesos que en cada uno de los años estudiados alcanzaron un mayor resonancia, es decir 44 homicidios (ver anexo 1).

A la hora de abordar metodológicamente esta investigación y elaborar la ficha de trabajo, se han tenido especialmente en cuenta las propuestas que sobre análisis de contenido realizan tanto Wimmer y Dominick (1996: 168-168) como Gaitán y Piñuel (1998: 281-311). Para la selección de las unidades de estudio se han respetado los siguientes criterios:

1. La presencia de la noticia en todos o casi todos los medios seleccionados.

2. Se han priorizado aquellos hechos que hayan atraído la atención de la prensa durante varios días (el caso más longevo fue el asesinato de Amaia Azkue que concitó el interés de los periódicos durante 14 meses, entre marzo de 2011 y mayo de 2012).

3. La ubicación de los mismos en las portadas de las publicaciones.

2 Estas cifras han sido obtenidas de las Memorias anuales del Instituto Vasco de Medicina Legal, de la web del Ministerio del Interior y de los datos facilitados por la Dirección de Atención a las Víctimas de la Violencia de Género, dependiente del Gobierno Vasco. 
4. El equilibrio entre los territorios del País Vasco, a fin de buscar la mayor representatividad posible. De los homicidios seleccionados (50\%) ocurrieron en Bizkaia $^{3}$ o tuvieron como víctimas a personas de este territorio, 15 (34\%) acaecieron en Gipuzkoa y 7 (16\%) en Álava. Esta distribución mantiene un paralelismo con la demografía del País Vasco, en donde Bizkaia cuenta con el 53\% de la población, Gipuzkoa con el 32\% y Álava con el 15\%.

Los medios analizados son El Correo Español, El Diario Vasco, Deia, Diario Noticias de Álava, Noticias de Gipuzkoa, Gara, El Mundo del País Vasco y El País (edición del País Vasco). Estos diarios acaparan aproximadamente el $90 \%$ de la difusión de la prensa de Euskadi y el $82,3 \%$ de la audiencia (el 91,3\% si no se tuviesen en cuenta los diarios deportivos).

Según La OJD el número de lectores (en miles) de la prensa en el País Vasco en 2012 se distribuyó de la siguiente manera:

\begin{tabular}{||l|l||}
\hline \hline Diario & Difusión \\
\hline \hline El Correo (Vocento) & 90.377 \\
\hline \hline El Diario Vasco (Vocento) & 63.406 \\
\hline \hline Deia (Noticias) & 15.561 \\
\hline \hline Gara & - \\
\hline \hline Noticias de Gipuzkoa (Noticias) & - \\
\hline \hline Diario Noticias de Álava (Noticias) & 6.239 \\
\hline \hline El País (edición País Vasco) & 4.263 \\
\hline \hline El Mundo (edición País Vasco) & 10.981 \\
\hline \hline
\end{tabular}

Algunas de estas cabeceras pertenecen al mismo grupo editorial, lo que les permite compartir contenidos. Así Vocento publica El Correo, editado en Bizkaia, pero con una importante edición para Álava que cuenta con un elevado número de páginas diferenciadas, y El Diario Vasco, cuya sede está en San Sebastián. El Grupo Noticias dispone de una cabecera distinta para cada uno de los tres territorios vascos: Deia en Bizkaia, Noticias de Gipuzkoa, y Diario de Noticias de Álava. Gara y El País (edición País Vasco) ofrecen una misma versión para toda la Comunidad, mientras que $E l$ Mundo del País Vasco ha llegado a contar con ediciones provinciales, pero en 2005 cerró las de Álava y Gipuzkoa.

La existencia de dos grupos -Vocento y Noticias- con cabeceras o ediciones específicas para las distintas provincias vascas ha aconsejado realizar el análisis sobre cinco bloques de diarios: Grupo Vocento (El Correo y El Diario Vasco), Grupo Noticias (Deia, Noticias de Gipuzkoa y Diario Noticias de Álava), Gara, El País (edición País Vasco) y El Mundo del País Vasco. Se ha tomado como objeto de análisis la ca-

${ }^{3}$ Un vecino de Sopuerta (Bizkaia) apareció degollado en Castro Urdiales (Cantabria) y un joven de San Sebastián murió apuñalado en Lekunberri (Navarra).

4 Gara no aparece en los controles de OJD. 
becera o edición del territorio en el que se producía el homicidio. Así, para una muerte acaecida en Gipuzkoa se han analizado El Diario Vasco, Noticias de Gipuzkoa, Gara, El País y El Mundo del País Vasco. Si el suceso se producía en Bizkaia, los dos primeros rotativos eran sustituidos, respectivamente, por El Correo (edición Bizkaia) y Deia. Por último, en el caso de Álava se ha acudido a la edición específica de $E l C O$ rreo para ese territorio y a Diario Noticias de Álava.

En todo caso, el máximo de días analizados para cada uno de estos sucesos ha sido de tres por diario seleccionado, lo que arrojaría un máximo de 660 ejemplares revisados (44 sucesos x 5 diarios x 3 días).

\subsection{Ficha de análisis}

El análisis de contenido se ha formulado mediante una ficha de registro (ver anexo 2), en la que se han volcado aquellos datos relativos al encuadre formal de las noticias: número de días, número de páginas, espacio ocupado y apertura o no de página. Se trata de aspectos referidos a la relevancia otorgada por cada diario a la información.

Asimismo, y aunque por cuestiones de espacio no se analizan en este artículo, se han consignado también, el género de las informaciones, tipo de titulares, así como la autoría de los textos.

Las categorías que inciden directamente en la adecuación o no de los contenidos a las buenas prácticas en esta materia son tanto de carácter léxico como visual. A tal fin se ha llevado a cabo una revisión teórica de los libros de estilo de los diferentes diarios estudiados, así como de las compilaciones sobre recomendaciones y códigos deontológicos que afectan directamente a las categorías estudiadas (Pérez Fuentes, 2004).

Desde la teoría del framing, se ha puesto en evidencia la importancia de los recursos visuales (fotos, gráficos, infografias) como dispositivos de encuadre (ver Gamson y Modigliani, 1989 y Tankard, 2001). Además, se ha diferenciado entre las inserciones realizadas en la portada y las ubicadas en el interior de las publicaciones.

A la hora de estudiar las características de las fotografías empleadas hemos recurrido a la metodología propuesta por Javier Marzal en lo referente al nivel morfológico. Como apunta este autor, "el análisis propiamente dicho de la fotografía debe comenzar con una descripción del motivo fotográfico, es decir, de lo que la fotografía representa en una primera lectura de la imagen" (Marzal, 2007: 181). Se han establecido 5 encuadres temáticos distintos en lo que respecta a las fotografias: víctima, agresor, escenario, repulsa/dolor y otros.

La presunción de inocencia, así como la identidad de la víctima y de los agresores están incluidas en la ficha, matizando su denominación con siglas o nombre completo. Otros componentes léxicos que competen al objetivo de este estudio son la inclusión o no, tanto en titulares como en el cuerpo de la noticia de términos como asesinato u asesinado. Por último la ficha deja un espacio para aquellas observaciones de carácter cualitativo que pudiesen enriquecer la investigación.

Para comprobar la fiabilidad de la utilización de dicha ficha por parte de los investigadores ( 3 en este caso) se ha utilizado el método Holsti que, como explica Juan José Igartua, "se utiliza para calcular el grado de acuerdo alcanzado entre dos codificadores" (Igartua, 2006: 231). 
En nuestro caso, el citado método respondería a la siguiente fórmula:

$$
\text { Coeficiente de Acuerdo }=\frac{3 A}{n_{1}+n_{2}+n_{3}}
$$

$3 \mathrm{~A}$ corresponde al número de acuerdos entre los tres codificadores, mientras que $\mathrm{n}_{1}+\mathrm{n}_{2}+\mathrm{n}_{3}$ indica el número total de unidades analizadas por cada uno de ellos. En la comprobación realizada, los tres codificadores coincidieron en 23 mediciones de un total de 27. Por lo tanto la aplicación del método de Holsti nos daría el siguiente cálculo:

$$
\text { Coeficiente de Acuerdo }=\frac{3 \times 23}{27+27+27}=0,85
$$

Según explica Igartua "el nivel de acuerdo mínimo que se debe alcanzar para que los datos sean fiables es de $0.80(80 \%)$ " (2006: 221$)$, por lo que en la prueba de fiabilidad el umbral queda superado.

\section{La presunción de inocencia}

La utilización del adjetivo presunto junto al nombre homicida, asesino o culpable es motivo de controversia en los libros de estilo de los medios de comunicación. La Vanguardia o $A B C$, por ejemplo, reconocen la conveniencia del uso de presunto "para indicar que algo no ha sido comprobado" $(A B C, 1993: 121)$ o en relación al "acusado de un delito hasta que se celebre el juicio" (La Vanguardia, 2004: 254). El País, sin embargo, limita su uso al momento en que se han abierto diligencias judiciales, "si no se le han abierto todavía, es supuesto delincuente" (El País, 2004: 437). En el mismo sentido, la agencia EFE, en su Libro del Estilo Urgente, se inclina por el término, supuesto, "idóneo cuando se trata de causas penales sin sentencia firme, o bien escoger el que resulte adecuado a cada fase del proceso, como «sospechoso», «detenido», «imputado», «procesado» o «acusado». Conviene evitar el uso de la palabra «presunto» que jurídicamente contraría el concepto de la presunción de inocencia" (2011: 40).

En 1764, Cesare Beccaria en su obra De los delitos y las penas, dejó sentadas las bases de este concepto jurídico, observando que "un hombre no puede ser llamado culpable antes de la sentencia del juez, ni la sociedad puede quitarle la protección pública sino cuando se haya decidido que violó los pactos con los que aquella protección fue acordada" (Beccaria, 1764, ed. 2002: 60).

La presunción de inocencia fue posteriormente recogida en el artículo 9 de la $D e-$ claración de los Derechos del hombre y del ciudadano en 1789, así como en el artículo 11.1 de la Declaración Universal de Derechos Humanos de 1948, el artículo 6.2 del Convenio de Roma para la Protección de los Derechos humanos y Libertades Fundamentales de 1950, entre otros. Asimismo, la Constitución española en su artículo 24 establece el derecho de todas las personas a no confesarse culpables así como a la presunción de inocencia. El Código Deontológico de la FAPE (Federación de Asociaciones de Periodistas de España) especifica que "el periodista debe asumir el principio de que toda persona es inocente mientras no se demuestre lo contrario y evitar al máximo las posibles consecuencias dañosas derivadas del cumplimiento de sus deberes informativos".

Sin embargo y pese a la claridad de estas disposiciones en ocasiones los medios de comunicación hacen un uso coloquial del término, dando por sentado que denominar 
presunto asesino o homicida al sospechoso o imputado en un delito salvaguarda su presunción de inocencia, si bien lo que estas presumiendo es la culpabilidad del mismo. Como muy bien dice Frances Barata "La presunción de inocencia es un logro de la civilización que continúa siendo difícil de entender para la sociedad y es aplicado de forma contradictoria y errática en el periodismo" (Barata, 2009: 218).

Los resultados del análisis realizado muestran cómo es una práctica más o menos habitual en la prensa utilizar el término presunto para referirse a sospechosos o imputados en los casos de homicidio o asesinato. Si bien su presencia en titulares es ostensiblemente menor, casi la mitad, excepto en el grupo Vocento, que alcanza un $27,27 \%$, seguido de Noticias con un 13,63\%. En el resto de los grupos se menciona en cifras absolutas en 5 casos de los 44 estudiados, en un 11,36\%.

Gráfico 1: Porcentaje de titulares y textos en los que aparece el término "presunto"

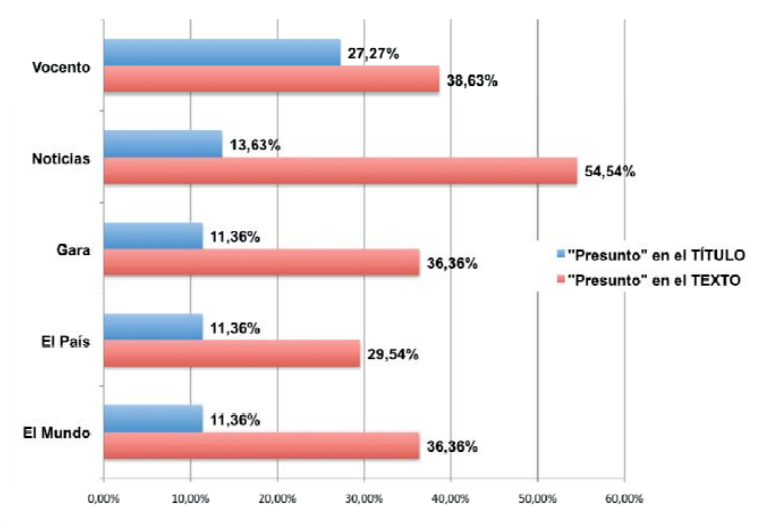

Fuente: Elaboración propia

Respecto al uso del término "presunto" en los textos, el grupo Noticias encabeza el ranking con un $54,54 \%$, seguido de Vocento con un $38,63 \%$. Hay que destacar que tanto El Mundo como Gara coinciden en sus porcentajes, 36,36\%, siendo el menos proclive a utilizarlo El País con un $29,54 \%$. Del análisis diacrónico se desprende que no hay una evolución en la frecuencia de las apariciones y se puede relacionar su mayor aparición con aquellos crímenes en los que el sospechoso o sospechosa es detenida con cierta celeridad.

\section{Asesinato/homicidio}

Otro aspecto analizado ha sido el empleo de conceptos como asesino y sus derivados asesinato $u$ asesinado, tanto en textos como en titulares. De nuevo, el lenguaje jurídico es muy estricto al distinguir entre homicidios o asesinatos. Los primeros hacen referencia a la muerte de una persona a manos de otra, que puede haber tenido lugar con intencionalidad o sin ella, homicidio voluntario o involuntario, sin embargo el asesinato cuyo castigo implica una pena mayor, conlleva además la concomitancia de alguna de estas circunstancias: alevosía; por precio, recompensa o promesa; con ensañamiento, aumentando deliberada e inhumanamente el dolor del ofendido. A pesar 
de que los distintos libros de estilo hacen hincapié en la necesidad de mantener el rigor informativo -definido por el Libro de Estilo de Vocento como "la adecuación de la información a la realidad (Pérez, 2004: 229)- es muy habitual que los diarios analizados utilicen los términos "asesinato" y "homicidio" como sinónimos.

Gráfico 2: Porcentaje de titulares y textos en los que aparece el término "asesino/asesinato"

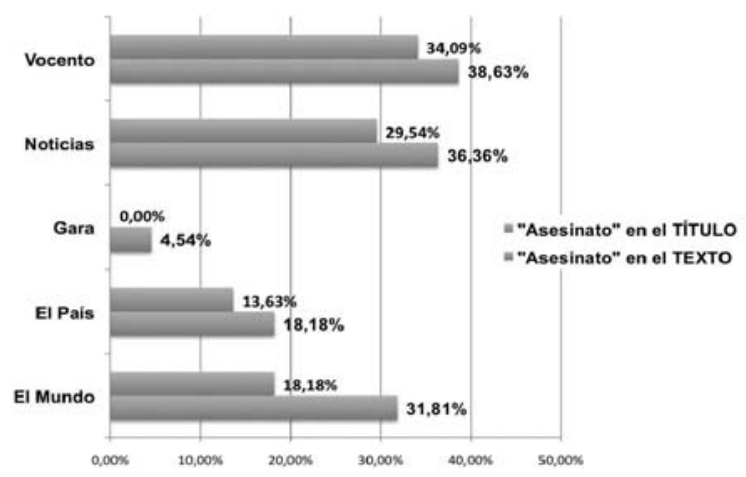

Fuente: Elaboración propia

En este sentido, se observa que los grupos Vocento y Noticias son los más proclives a incluir la palabra "asesinato" en sus titulares, con un $34,09 \%$ y un $29,54 \%$, respectivamente. En cifras absolutas este tipo de titular se recoge en 15 y 13 de los 44 casos analizados. Ambos grupos no dudan en reproducir también este vocablo o su en portada. El 19 de mayo de 2009, Noticias de Gipuzkoa titulaba "Asesinado a golpes en su borda un vecino de Berrobi", y sobre el mismo hecho El Diario Vasco, también en primera página, tituló: "Un hombre de 59 años, asesinado al ser golpeado con un mazo de hierro en una borda de Berrobi". El Mundo es el diario de tirada nacional más próximo a esta política informativa, seguido de El País, que reduce casi a la mitad sus porcentajes.

En los textos también se mantiene el mismo orden, incrementándose incluso los porcentajes. Así, Vocento recurre al término asesino o habla de asesinato en el 38,63\% de los crímenes. Gara es el único diario que no incluye este vocablo en sus titulares y apenas lo destaca en el cuerpo de la noticia. Cabe recordar que esta cabecera tampoco solía utilizar los términos "asesino/asesinato" en las muertes provocadas por ETA, lo que unido al escaso interés mostrado por las noticias sobre homicidios, explica el exiguo $4,54 \%$ que aparece en el cuadro 2 .

No se aprecia una evolución, ni incremento destacable de un año a otro, si bien la especial crudeza de algunas muertes y las circunstancias truculentas que les rodean, impulsan a los informadores, aunque no siempre ni en todos los medios por igual, a recurrir a estos conceptos.

\section{La identidad de la víctima o del agresor}

Otro aspecto reseñado en la mayoría de los libros de estilo y también sujeto a controversia, es el que atañe a la identidad tanto de la víctima como del supuesto homicida. 
Así, en nombre de la deontología periodística, a menudo se invita a los medios a que mantengan una cierta prudencia a la hora de ofrecer los nombres de los sospechosos de un delito grave, al menos, hasta que no exista una imputación judicial al respecto. Sin embargo, lo habitual es encontrarse en las informaciones no sólo con los nombres y apellidos de los detenidos, sino incluso con detalles tales como su nacionalidad o etnia.

En la normativa deontológica periodística, como recuerda Maciá Barber, "por lo general se aboga por mantener el anonimato del implicado, salvo que su mención resulte esencial para completar la noticia o por el carácter público del sospechoso" (2010: 122). La reproducción del nombre por parte de los representantes o allegados del acusado también justificaría su publicación, y en última instancia, "cuando no está claro cómo proceder, el periodista y los responsables de redacción evaluarán las particularidades de cada caso, desde el delito cometido y sus circunstancias a la información facilitada oficialmente" (EFE, 2011: 39).

Gráfico 3: Porcentaje de sucesos con mención de siglas o nombres del agresor y/o la víctima

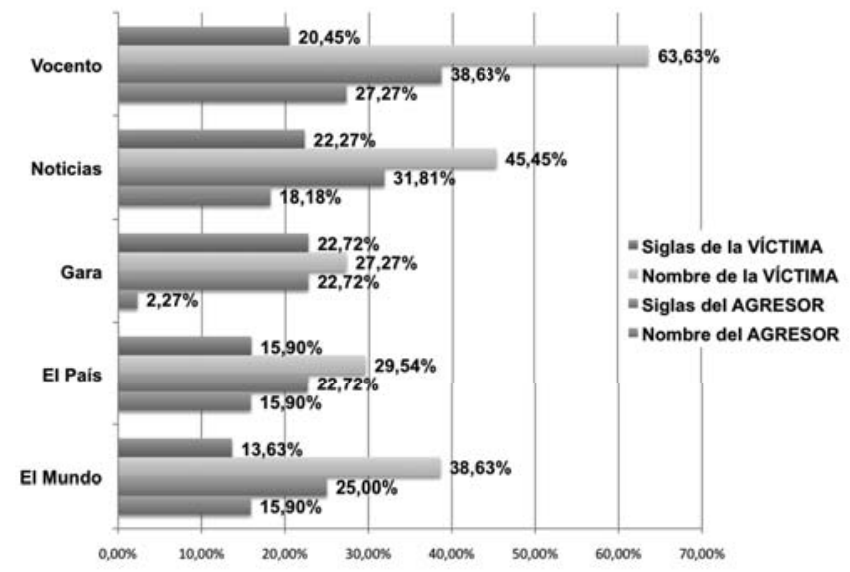

Fuente: Elaboración propia

Vocento es el grupo más proclive a dar el nombre completo del agresor, lo hace en un $27,2 \%$, es decir en 12 de los sucesos analizados. Noticias lo hace en un $18,1 \%$, en 8 ocasiones, y le siguen con el mismo número de casos (7) El Mundo y El País. Gara, de nuevo, será el medio más comedido, con una sola mención.

En todos los diarios el informador se decanta en más ocasiones por dar sólo las siglas del supuesto homicida, ya sea por desconocimiento preciso de su identidad o por decisión propia.

Aunque dar el nombre de la víctima aparentemente no revista la misma trascendencia que en el caso de los acusados, también hay voces que abogan por mantener el anonimato de las mismas. El grupo Vocento en su Libro de Estilo, agrupa a víctimas y sospechosos bajo el paraguas de "implicados" y aboga indistintamente para ambos por el respeto a la intimidad de las personas, aludiendo directamente a las informaciones de sucesos. "En informaciones de sucesos, se omitirá el nombre de los implicados y se sustituirá por las iniciales, excepto si el asunto afecta a personas de 
relevancia pública o con responsabilidades políticas o institucionales" (Pérez, 2014: 314). Precisamente es el grupo Vocento, quien en mayor medida ofrece los nombres y apellidos de las víctimas, $63,63 \%$ de los casos estudiados, seguido por Noticias con un 45,45\% y El Mundo con un 38,63\%, 17. A continuación se sitúan El País (29,54\%) y $\operatorname{Gara}(27,27 \%)$, Sólo en este último diario son iguales los porcentajes de apariciones del nombre y de las siglas de la víctima. En el resto de la prensa, se opta más a menudo por dar la filiación detallada.

\section{El origen de la víctima y el sospechoso}

El origen de la víctima y del sospechoso también son destacados en algunos diarios. Aunque el consenso en este punto es total y tanto desde el ámbito académico como profesional se insiste en la necesidad de no subrayar el origen, etnia o procedencia de los implicados, dado que es una información en general irrelevante que sólo sirve para ahondar en estereotipos y prejuicios hacía determinados grupos, la práctica contradice todas estas apreciaciones. De hecho ningún diario está exento de mencionar el origen del agresor en al menos $6(13,63 \%$ de los sucesos estudiados, como ocurre con Gara. El resto de los medios, al menos, duplica ese porcentaje: El Mundo y El País, $(27,27 \%)$.

Como señala Villalobos Molina, "el binomio delincuencia inmigración es un discurso especialmente eficaz. Es una generalización muy creíble y políticamente rentable que está relacionada con otros discursos acerca de los inmigrantes, que se manejan en los terrenos del desconocimiento y del miedo" (Villalobos, 2005: 159).

Gráfico 4: Nacionalidad del agresor y la víctima

Fuente: Elaboración propia

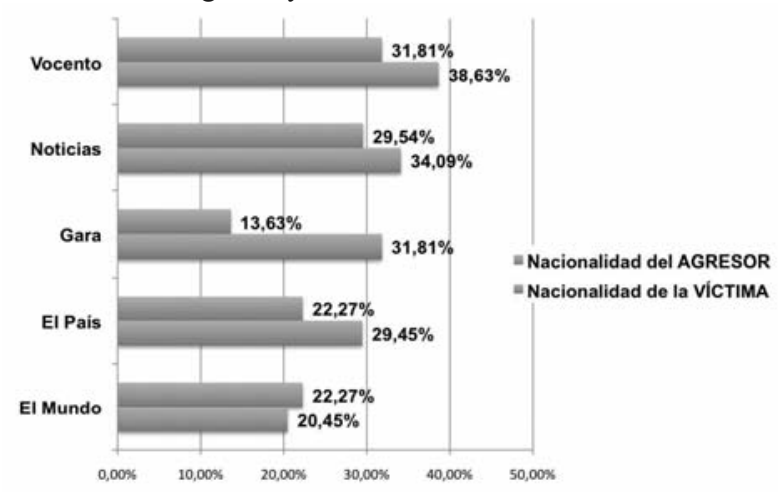

Los grupos Vocento y Noticias, son los que más alusiones hacen a la nacionalidad y origen de la víctima y del agresor tanto en los titulares como en el cuerpo de la noticia. Ucraniano, marroquí, colombiano, camerunés, iraní o guineano, es, entre otras, la procedencia de algunos de los acusados de estos crímenes, y si bien su origen no puede ser considerado una información sustancial para comprender lo sucedido, sí que refuerza los estereotipos, forjando la imagen del inmigrante como un ser culturalmente distinto e intrínsecamente violento. 
El 18 de abril de 2006 El Diario Vasco incluye en el titular tanto de portada como de las páginas interiores la nacionalidad de la víctima. "Fallece un joven ucraniano apuñalado en plena calle de San Sebastián". Del mismo grupo Vocento, El Correo, el 25 de junio de 2007, titula: "Muere una joven colombiana degollada por un compatriota de 19 años en un bar de Bilbao". El Mundo el 19 de abril de 2006, dice "Detenido un ucraniano como autor de la muerte de un compatriota en San Sebastián".

El País el 23 de diciembre de 2009 en la cobertura de la muerte de una anciana en un caserío de Urduliz señala que "quedaría descartada, de momento, la participación de una banda de rumanos que ya fue detenida. Eso sí, no está confirmada que en esta ocasión los asaltantes sean de raza negra aunque es una de las hipótesis de trabajo".

Deia el 16 de mayo de 2010 recoge declaraciones de testigos, en relación a la muerte de un joven de un navajazo en Barakaldo, en las que se afirma: "los sudamericanos eran bajitos y estaban agresivos, con los cintos en la mano". Aunque se trata de casos aislados, este tipo de observaciones no están exentas de connotaciones xenófobas. No hay que olvidar que, como señalan Igartua et al. después de analizar el tratamiento informativo de la inmigración en cinco periódicos nacionales, El Mundo, El País, ABC y La Razón, entre los cinco encuadres noticiosos más destacados aparece: "los inmigrantes como delincuentes y vinculados con mafias u organizaciones delictivas" (2005: 166). Cuando los implicados en el suceso son de etnia gitana también se destaca este hecho, como ocurrió en la reyerta ocurrida en Eibar el 14/12/2007.

\section{Encuadres visuales: fotografía y crimen}

Por lo que respecta al empleo de fotografías en las páginas de los medios, en la muestra estudiada se han contabilizado un total de 394 fotografías. Han sido analizados tanto su tamaño como contenido. En lo referente a este último aspecto se han contemplado los siguientes encuadres temáticos: víctima/cadáver, agresor, escenario, repulsa/dolor y se ha creado un apartado de "otros contenidos".

Las diferencias son notables entre los diferentes medios. Los diarios estudiados de Vocento incluyeron un total de 179 fotografías, mientras que El País únicamente insertó 17. A medio camino se situaban el grupo Noticias con 122, El Mundo con $47 \mathrm{y}$ Gara con 29. El año con mayor número de imágenes fue 2011 con 97, más del doble de las que aparecen en 2010 (48) y 2005 (45). La acción protagonizada por un perturbado en Santutxu el 14/11/2011, que acabó con la vida de un maestro jubilado y causó heridas de arma blanca a otras seis personas, conllevó que sólo El Correo ya publicase 31 imágenes durante los tres días posteriores al suceso.

Si reparamos en el promedio de fotos publicadas por homicidio durante el máximo de tres días estudiados para cada caso, se comprueba que mientras Vocento alcanza las 4, ni Gara ni El País llegan a la unidad. El incremento o no del uso del material gráfico para ilustrar los homicidios depende fundamentalmente de dos variables: La primera son los años. De 2002 hasta 2009 -salvo en 2005- el promedio de fotografías publicadas por Vocento oscila entre las 2 y 3 por homicidio. A partir de 2010 se produce un salto cualitativo y la media se incrementa hasta las 5 o 6 .

La segunda variable es el tipo de homicidio: en diciembre de 2005 Vocento publica 18 fotografías para ilustrar la muerte de un taxista en Bilbao; en octubre de 2010 
inserta 9 para acompañar los textos sobre la muerte de una niña encontrada en una playa de Zarautz; y también en octubre, pero de 2011, incluye 31 para ilustrar las noticias sobre el acuchillamiento de siete personas en Santutxu que ocasionó la muerte de un maestro jubilado.

Esta pauta es mantenida también por el grupo Noticias que desde 2002 hasta 2009 -excepto en 2005- ofrece un promedio que oscila entre 1 y 2, pero a partir de 2010 pasa a publicar una media de 5 por homicidio. En octubre de 2011 publica un total de 21 para ilustrar el acuchillamiento mortal de un jubilado por un perturbado en el barrio bilbaíno de Santutxu.

El resto de diarios se mueve en porcentajes tan bajos que sus variables no resultan significativas, aunque también incrementan sus fotografías cuando los acontecimientos son especialmente relevantes.

Marauri, Rodríguez y Cantalapiedra (2011a) realizaron un estudio sobre la cobertura fotográfica de los sucesos en los diarios españoles entre 1977 y 2000 y entre las conclusiones de dicho trabajo figura el incremento del peso cualitativo de la imagen dentro de la página: "Se ha comprobado que a lo largo de las más de dos décadas objeto de estudio se ha producido un aumento de la relevancia de la fotografía en la página, plasmada en un crecimiento de la proporción de imágenes de mayor tamaño" (2011a: 527).

\begin{tabular}{|l|l|l|l|l|l|}
\hline \multicolumn{5}{|c|}{ Cuadro 1: Temática de las fotografías de páginas interiores } \\
\hline Grupo & Víctima & Agresor & Escenario & Repulsa & Otros \\
\hline Vocento & 45 & 7 & 64 & 36 & 27 \\
\hline Noticias & 14 & 3 & 59 & 24 & 22 \\
\hline Gara & 7 & - & 12 & 6 & 4 \\
\hline El País & 6 & - & 10 & - & 1 \\
\hline El Mundo & 8 & 2 & 24 & 11 & 2 \\
\hline TOTAL & 76 & 12 & 178 & 67 & 61 \\
\hline & $\%$ sobre & $\%$ sobre & $\%$ sobre su & $\%$ sobre & $\%$ sobre \\
& su total & su total & total & su total & su total \\
\hline Vocento & $25,1 \%$ & $3,9 \%$ & $35,8 \%$ & $20,1 \%$ & $15,1 \%$ \\
\hline Noticias & $11,5 \%$ & $2,5 \%$ & $48,3 \%$ & $19,7 \%$ & $21,3 \%$ \\
\hline Gara & $24,1 \%$ & - & $41,3 \%$ & $20,6 \%$ & $13,7 \%$ \\
\hline El País & $35,3 \%$ & - & $58,8 \%$ & - & $5,9 \%$ \\
\hline El Mundo & $17,0 \%$ & $4,2 \%$ & $51,1 \%$ & $23,4 \%$ & $4,2 \%$ \\
\hline \multicolumn{7}{|l|}{} & Fuente: Elaboración propia & \\
\hline
\end{tabular}

Sobre las temáticas más habituales que abordan las fotografías publicadas hay que destacar algunos aspectos de interés. Las más recurrentes utilizadas por todos los medios analizados son las que ilustran los escenarios de los homicidios. Se trata de un material que no tiene un alto valor periodístico porque se limita a reproducir el lugar en el que ocurrió el crimen. Además es muy fácil de obtener, aunque es cierto que contribuye más o menos eficazmente al acompañamiento de los textos. Más de la mitad de las instantáneas que publican El País, El Mundo y el grupo Noticias corresponde 
a este tipo de imágenes. El grupo Vocento, con un 35,8\% sobre su total, es el que menos emplea a este tipo de foto.

Vocento no utiliza las fotografías del escenario como recurso ante la inexistencia de otro material visual, sino complemento al ya disponible. Esto es así porque excepto en 2005, siempre que reproduce el lugar del homicidio aporta también imágenes de características diferentes.

El grupo Noticias, sin embargo, sí utiliza, aunque de forma ocasional, las fotografías de escenario como recurso cuando carece de otros elementos. Esta tendencia se acentúa y queda claramente marcada en Gara, El País y El Mundo.

El segundo bloque de fotografías corresponde a la víctima. Se trata de un material de gran interés periodístico pero que no es fácil conseguir, ya que exige el desplazamiento inmediato de los fotógrafos al lugar de los hechos o que los familiares del fallecido pongan a disposición del medio imágenes de la víctima, cosa que no siempre es sencilla. El alto porcentaje de este tipo de instantáneas demuestra claramente el interés y esfuerzo por conseguirlas por parte de los medios de comunicación.

El problema que puede plantearse con las imágenes de las víctimas es que en ocasiones existe el riesgo de caer en planteamientos sensacionalistas. Como destaca el Libro del Estilo Urgente de la Agencia EFE, "la violencia, la obscenidad, la tragedia, las ofensas a la dignidad y la miseria humana no deben servir de gancho para publicar nuestras fotos ni protagonizarlas de forma gratuita" (2011: 58).

Sobre los porcentajes utilizados por este tipo de instantáneas por las diferentes cabeceras hay que hacer unas matizaciones. Los altos niveles de fotos de víctimas de $E l$ País, Gara y El Mundo se debe al bajo número de fotos que publican y al uso que hacen de las de agencia, por lo que no determinan directamente el interés del medio.

Con la salvedad de El País, por las razones apuntadas, es el grupo Vocento es el que publica un porcentaje más alto de imágenes de las víctimas. Excepto en 2009, a lo largo de todos los años estudiados este grupo mediático inserta fotografías de las víctimas, en algunos casos en número considerable como en 2011, año en el que alcanzó la decena.

El grupo Noticias muestra también interés por este material gráfico, aunque no alcanza las cifras de Vocento. El resto de los medios, sin excepciones, publica también este tipo de fotografía, aunque en un nivel muy inferior.

Hay que decir que, mientras que en las informaciones sobre violencia de género, decálogos y recomendaciones coinciden en acentuar la necesidad de prescindir de este tipo de imágenes, que victimizan a la mujer y dan una impresión de fatalismo y derrota; en el caso de las muertes que nos ocupan los criterios no están tan claros. El interés informativo, o el criterio del periodista o director de la publicación se sugieren como coartadas respetables en muchos de los libros de estilo consultados.

Una mención especial merecen las fotografías en las que aparece el agresor. Se trata de imágenes excepcionales que muy raramente pertenecen al presunto homicida instantes después de cometer su delito. Hay que tener en cuenta que en algunos casos se desconoce quién es el autor del crimen hasta pasado un tiempo. Existen asimismo homicidios protagonizados por menores y la legislación española protege especialmente el derecho a la propia imagen de este colectivo. Ana Azurmendi recuerda al 
respecto que "nombres, fotografías actualizadas, informes psicológicos, intentos de fuga o comisión de infracciones durante el periodo de reeducación son objeto de noticias de suscesos en los medios de comunicación. La conclusión a la que llevan estas informaciones tiene un doble cariz: por un lado se considera imposible la reinserción de estos jóvenes que han demostrado una capacidad excepcional para la violencia; por otro se mantiene la alerta frente al peligro que, al menos en apariencia, siguen representando (Azurmendi, 2008: 206).

Por su parte, la agencia EFE apunta la necesidad de "sopesar la justificación informativa de las fotos de personas esposadas, que pueden vulnerar la presunción de inocencia y el derecho al honor y la propia imagen si se trata de acusados sin una condena firme" (EFE, 2011: 58). Por todo ello, el porcentaje de imágenes de los supuestos homicidas es bajo, pero una vez más es Vocento el que hace un esfuerzo superior para conseguir a este tipo de material gráfico.

Sobre las imágenes que reflejan la repulsa o el dolor por el suceso, más allá de los datos porcentuales en los que destacan por encima de los demás Gara y El Mundo, debido una vez más al escaso número de fotografías que publican, se pueden resaltar otros dos elementos significativos. Por un lado, el grupo Vocento, excepto en 2003, siempre incluye instantáneas en las que aparece reflejado el dolor o la repulsa de familiares o amigos. Por otro, El País se sitúa en el extremo contrario y nunca, en la muestra seleccionada, inserta fotografías de este tipo.

\section{Conclusiones}

1. La mayoría de los medios ha reflexionado sobre la presunción de inocencia, así como sobre la conveniencia de utilizar un léxico ajustado a la legalidad en sus libros de estilo. Sin embargo, en la práctica profesional dichas recomendaciones son frecuentemente obviadas. Los diarios de los grupos Noticias $(13,63 \%$ y $54,54 \%$ de los casos) y Vocento $(27,27 \%$ y $38,63 \%)$ son los que más utilizan el término "presunto" en titulares y textos. En unos porcentajes muy similares se sitúan Gara (11,36\% y $36,36 \%)$, El País (11,36\% y $29,54 \%$ ) y El Mundo (11,36\% y 36,36\%).

2. Del mismo modo, calificar de asesino o definir como asesinato la muerte de la que se informa es también más frecuente en los grupos Vocento y Noticias, que emplean estos términos en sus titulares en un 34,09\% y 29,54\%, respectivamente, de las muertes tratadas. Gara es el único medio que nunca emplea este vocablo en sus titulares, aunque sí lo hace en el cuerpo de la noticia, en 4 de los 44 homicidios estudiados. El resto de los diarios aumenta sus porcentajes en el interior de sus páginas donde es más frecuente hallar la palabra asesino o sus derivados para describir al suceso y al acusado.

3. La publicación de la identidad de víctimas y sospechosos es motivo de debate en los ámbitos jurídicos y periodísticos. Aunque los libros de estilo en general se inclinan por mantener el anonimato de los sospechosos, lo cierto es que no hay un solo medio que mantenga esta postura en todos los casos estudiados. De entre todos ellos Vocento es el más proclive a dar el nombre y apellido de las víctimas, lo hace en al menos 12 crímenes, seguido de Noticias con 8 y El Mundo y El País, ambos con 7. Gara es de todos los diarios el más cauto, con una sola mención. En cualquier caso, 
lo más frecuente es que el agresor sea identificado únicamente por sus siglas. Los grupos Vocento y Noticias son los menos reticentes a la hora de identificar a fallecidos y víctimas. Aunque, en principio, la identificación de las víctimas puede plantear menos problemas que la de los presuntos agresores, se trata de un tema delicado en la medida en que también afecta a la familia y allegados del fallecido. Todos los diarios excepto Gara optan por dar el nombre y apellido en más ocasiones que las siglas.

4. En lo que respecta a la inclusión de datos relativos al origen tanto del acusado como de la víctima, Gara es el diario más cauto, con 6 referencias al origen del acusado. El resto oscila entre el $31,81 \%$ de Vocento y el $27,7 \%$ de El Mundo y El País. Aunque la procedencia o la etnia del acusado no se ofrece mayoritariamente, ningún periódico evita dar detalles con posibles connotaciones xenófobas en alguno de los casos estudiados. Cuando se trata de informar sobre la víctima las cifras en todos los diarios se duplican.

5. Vocento y Noticias son los grupos mediáticos que más uso hacen del material gráfico para ilustrar las informaciones de homicidios. Las imágenes del escenario de los hechos son las más utilizadas por todos los diarios, seguidas por las de las víctimas y las de los actos de repulsa. Preferentemente se opta por inserciones de 2 ó 3 columnas. También las fotografías a 4 columnas tienen una presencia digna de mención, excepto en el caso de El País. Menos frecuente, e incluso inexistente en algunos casos, es encontrar la imagen del agresor, aunque los grupos Vocento y Noticias la ofrecen en 7 y 3 ocasiones, respectivamente.

6. Todos los grupos incurren a lo largo de estos 11 años en alguna praxis que entraría en conflicto con las recomendaciones más habituales de libros de estilo y códigos deontológicos en relación con el tratamiento de los homicidios. En este aspecto, los grupos Noticias y Vocento aparecen como los más proclives a obviar dichas recomendaciones. Del análisis efectuado se desprende una falta de criterio que incide en ocasiones en un tratamiento arbitrario sujeto a las peculiaridades de algunos homicidios $\mathrm{y} / \mathrm{o}$ a las prácticas y rutinas profesionales.

\section{Referencias bibliográficas}

ABC (1993): Libro de estilo de ABC. Barcelona, Ariel.

ARMENTIA, José Ignacio; CAMINOS, José María; MARÍN, Flora y GANZABAL, María (2012): El tratamiento de las muertes violentas en la prensa vasca. ETA, violencia de género y siniestralidad laboral (1990-2010). Leioa, UPV/EHU.

AZURMENDI, Ana (2008): "La información sobre menores delincuentes y sus procesos judiciales", en EGÚSQUIZA, Ion y VIDAL, Vicente (coord.): El derecho a la información judicial. Valencia, Coso, pp. 201-219.

BARATA, Francesc (2003): "Los mass media y la información criminal. El "caso King" y las perversiones mediáticas". Quaderns del CAC, $\mathrm{n}^{\circ} 17$. Barcelona, Consell de l'Audiovisual de Catalunya, pp. 49-55.

BARATA, Francesc (2009): "La devaluación de la presunción de inocencia en el periodismo". Análisi, n. 39. Barcelona, Universitat Autònoma de Barcelona, pp. 217236. 
BARTHES, Roland (1977): "Estructura del suceso", en Ensayos críticos. Barcelona, Seix Barral, pp. 225-236.

BECCARIA, Cesare (1764, ed. 2002): De los delitos y las faltas. Barcelona, Ediciones Folio.

CUESTA, Ubaldo; CANEL, María José; GURRIONERO, Mario G. (eds., 2012): Comunicación y Terrorismo. Madrid, Tecnos.

EFE (2011): Libro del estilo urgente. Barcelona, Galaxia Gutenberg.

EL MUNDO (1996): Libro de Estilo de El Mundo. Madrid, Unidad Editorial.

EL PAÍS (2004): Libro de estilo de El País. Madrid, Ediciones El País.

FAPE (2010): Código deontológico. http://www.fape.es/codigo-deontologico.htm [fecha de consulta: 20 de mayo de 2013]

GAITÁN, Juan A. y PIÑUEL, José Luis (1998): Técnicas de investigación en comunicación social. Elaboración y registro de datos. Madrid, Síntesis.

GAMSON, William A y MODIGLIANI, Andre (1989): "Media discourse and public opinion on nuclear power: a constructionist approach". American Journal of Sociology, vol. 95, $\mathrm{n}^{\mathrm{o}}$ 1. Chicago, The University of Chicago Press, pp. 1-37.

GEKOSKI, Anna; GRAY, Jacqueline M; ADLER, Joanna R (2012): "What makes a homicide newsworthy?". British Journal of Criminology. vol. 52 (6), Oxford, Oxford University Press, pp. 1212-1232.

GREER, Chris \& McLaughlin, Eugene (2012): "Media justice: Madeleine McCann, intermediatization and 'trial by media' in the British press". Theoretical Criminology, vol. 16 (4). Londres, SAGE, pp. 395-416.

HERRERO, Carmen (2003): Periodismo de Sucesos y Tribunales. Tratamiento informativo de la violencia social. Sevilla, Padilla Libros editores y Libreros.

IGARTUA, Juan José (2006): Métodos cuantitativos de investigación en comunicación. Barcelona, Bosch.

IGARTUA, Juan José; MUÑIZ, Carlos y CHEN, Lifen (2005): “La inmigración en la prensa española. Aportaciones empíricas y metodológicas desde la Teoría del Encuadre Noticioso", Revista Migraciones, $\mathrm{n}^{\circ}$ 17. Madrid, Universidad de Comillas, pp. 143-181.

LA VANGUARDIA (2004): Libro de redacción. Barcelona, Ariel.

MACIÁ BARBER, Carlos. (2010): "El quehacer periodístico ante la presunción de inocencia", en ALSIUS, Salvador y SALGADO, Francesc (eds): La ética informativa vista por los ciudadanos. Barcelona, Editorial UOC, pp. 107-123.

MARAURI, Iñigo; RODRÍGUEZ, María del Mar; y CANTALAPIEDRA, María José (2011a): "La ilustración del dolor: cobertura fotográfica de los sucesos en los diarios de información general en España (1977-2000)". Estudios sobre el Mensaje Periodístico, vol. 17, $\mathrm{n}^{\circ}$ 2. Madrid, Servicio de Publicaciones de la Editorial Complutense, pp. 513-529. 
MARAURI, Iñigo; RODRÍGUEZ, María del Mar; CANTALAPIEDRA, María José (2011b): "Géneros informativos y estilo periodístico en la cobertura de sucesos en la prensa diaria de información general de España (1977-2000)". Zer. Revista de Estudios de Comunicación, vol. 16, n. 30. Leioa, Servicio Editorial UPV/EHU, pp. 213-227.

MARZAL, Javier (2007): Cómo se lee una fotografía. Interpretaciones de la mirada. Madrid, Cátedra

MINGOLARRA, José Antonio; AROCENA, Carmen; y MARTÍN, Rosa (eds., 2012): Violence and Communication. Reno, University of Reno.

MONTALBO, Juan Carlos (2012): "Los juicios paralelos en el proceso penal: ¿Anomalía democrática o mal necesario?". Universitas. Revista de Filosofía, Derecho y Política, $\mathrm{n}^{\circ}$ 6. Madrid, Universidad Carlos III, pp. 105-125.

PÉREZ FUENTES, Juan Carlos (2004): Ética periodística: Principios, códigos deontológicos y normas complementarias. Leioa, Universidad del País Vasco.

QUESADA, Montse (2007): Periodismo de sucesos. Madrid, Síntesis.

RODRÍGUEZ, Rosa (2011): "La información de sucesos. Temática en prensa escrita". Correspondencias \& Análisis, $\mathrm{n}^{\circ}$ 1. Suquillo (Perú), Universidad San Martín de Porres, pp. 309-325.

SCHILDKRAUT, Jaclyn \& DONLEY, Amy M. (2012): "Murder in Black: A Media Distortion Analysis of Homicides in Baltimore in 2010". Homicide Studies, vol. 16 (2). Londres, SAGE, pp. 175-196.

SUAREZ, Juan Carlos (2013): "La actitud ética de los periodistas andaluces ante cuestiones de especial sensibilidad social". Revista Latina de Comunicación Social, $\mathrm{n}^{\circ}$ 68. La Laguna (Tenerife), Universidad de La Laguna, pp. 309-328. En: http://www.revistalatinacs.org/068/paper/979_Sevilla/13_Suarez.html DOI: 10.4185/RLCS-2013-979 [Fecha de consulta: 8 de abril de 2014]

TANKARD, James (2001): "The empirical approach to the study of media framing", en S.D. Reese, O.H. Gandy y A.E. Grant (Eds): Framing Public Life. Mahwah, NJ: Lawrence Erlbaum, pp. 95-106.

TAYLOR, Catherine A. \& SORENSON, Susan B. (2002): "The nature of newspaper coverage of homicide". Injury Prevention, vol. 8 (2). Londres, BMJ, pp. 121-127.

VILLALOBOS, Cristina (2005): “Análisis de la representación del inmigrante delincuente en la prensa española de referencia. Obstáculos para la comunicación intercultural". Redes.com. Revista de Estudios para el Desarrollo Social de la Comunicación, $\mathrm{n}^{\circ}$ 2. Sevilla, Universidad de Sevilla-Universidad de Brasilia, pp.153-166.

WIMMER, Roger D. y DOMINICK, Joseph R. (1996): La investigación científica de los medios de comunicación. Una introducción a sus métodos. Barcelona, Bosch. 


\section{Anexo 1}

\begin{tabular}{|c|c|c|c|}
\hline \multicolumn{4}{|c|}{ Homicidios seleccionados (2002-2012) } \\
\hline Año & Fecha & Homicidio & Territorio \\
\hline \multirow{4}{*}{2002} & $24 / 03$ & Apuñalado vecino de Santurtzi en Castro & Bizkaia \\
\hline & $10 / 05$ & Apuñalada una mujer en un estanco de Elgeta & Gipuzkoa \\
\hline & $24 / 07$ & Un joven mata a otro en Trapagaran & Bizkaia \\
\hline & $16 / 11$ & Hallado el cuerpo de Elixabete Urbieta tras detener al presunto homicida & Gipuzkoa \\
\hline \multirow{4}{*}{2003} & $26 / 01$ & Muere un hombre de un disparo en la cabeza en Donostia & Gipuzkoa \\
\hline & $21 / 03$ & Apuñalado un joven en Pasaia & Gipuzkoa \\
\hline & $24 / 04$ & Muere un hombre en una disputa familiar en Portugalete & Bizkaia \\
\hline & $04 / 12$ & Asesinato del dueño del bar El Rioja & Álava \\
\hline \multirow{4}{*}{2004} & $15 / 03$ & Degollado por su gemelo en Mezkia & Álava \\
\hline & $25 / 05$ & Apuñalado un joven en Vitoria & Álava \\
\hline & $06 / 08$ & Mata a su hijo de 3 años en Vitoria & Álava \\
\hline & $24 / 08$ & Apuñalado toxicómano en Bilbao la Vieja & Bizkaia \\
\hline \multirow{4}{*}{2005} & $10 / 02$ & Detenido por matar a un conocido en Carranza & Bizkaia \\
\hline & $23 / 07$ & Mata a golpes a su padre en Maeztu por maltratar a su madre & Álava \\
\hline & $19 / 08$ & Matan a un marroquí en su piso de Vitoria & Álava \\
\hline & $12 / 12$ & Asesinado un taxista en Bilbao & Bizkaia \\
\hline \multirow{4}{*}{2006} & $02 / 01$ & Mata de una puñalada en el pecho a un joven en Bilbao & Bizkaia \\
\hline & $18 / 04$ & Fallece un joven ucraniano en Donostia & Gipuzkoa \\
\hline & $12 / 08$ & La Ertzaintza investiga el asesinato de una prostituta en Bilbao & Bizkaia \\
\hline & $15 / 12$ & Hallan el cuerpo de un vecino de Sopuerta degollado en Castro & Bizkaia \\
\hline \multirow{4}{*}{2007} & $05 / 03$ & Muere un joven de un navajazo en una zona de bares de Bilbao & Bizkaia \\
\hline & $07 / 05$ & La Ertzaintza investiga la muerte de un hombre acuchillado en Bilbao & Bizkaia \\
\hline & $25 / 06$ & Joven colombiana, degollada por un compatriota en Bilbao & Bizkaia \\
\hline & $15 / 12$ & Un muerto y tres heridos en una reyerta en Eibar & Gipuzkoa \\
\hline \multirow{4}{*}{2008} & $30 / 04$ & Hallan un cuerpo calcinado en una autocaravana en Lemoiz & Bizkaia \\
\hline & $18 / 08$ & Hallan muerto a un vecino tras el incendio de su vivienda en Lasarte & Gipuzkoa \\
\hline & $28 / 11$ & Tres detenidos por el asesinato de un joven en Sopuerta & Bizkaia \\
\hline & $02 / 12$ & Apuñalado en Galdakao & Bizkaia \\
\hline \multirow{4}{*}{2009} & $01 / 04$ & Apuñalado un hombre en Zierbana & Bizkaia \\
\hline & $17 / 05$ & Un hombre mata en Hernani al novio de su excompañera & Gipuzkoa \\
\hline & $19 / 05$ & Asesinado un hombre con un mazo de hierro en Berrobi & Gipuzkoa \\
\hline & $22 / 12$ & Muere una anciana en el asalto a su caserío de Urduliz & Bizkaia \\
\hline \multirow{4}{*}{2010} & $17 / 01$ & Joven donostiarra apuñalado en Lekunberri & Gipuzkoa \\
\hline & $16 / 05$ & Joven acuchillado en Barakaldo & Bizkaia \\
\hline & $22 / 08$ & Hayan un cadáver en Aia con signos de violencia & Gipuzkoa \\
\hline & $08 / 10$ & La Ertzaintza duda de la versión del padre de la niña muerta en Zarautz & Gipuzkoa \\
\hline \multirow{4}{*}{2011} & $15 / 03$ & Aparece el cadáver de Amaia Azkue en un embalse de Azpeitia & Gipuzkoa \\
\hline & $28 / 06$ & Un menor mata con un hacha a dos familiares en Portugalete & Bizkaia \\
\hline & $29 / 10$ & Un hombre halla una violenta muerte en Berrostegieta & Álava \\
\hline & $15 / 11$ & Un joven iraní acuchilla a un maestro jubilado en Santutxu & Bizkaia \\
\hline \multirow{4}{*}{2012} & $10 / 03$ & Un hombre aparece muerto en Mallabia & Bizkaia \\
\hline & $08 / 04$ & Investigan la muerte de un vecino de Lasarte de un disparo & Gipuzkoa \\
\hline & $02 / 05$ & Muerto a golpes en Barakaldo & Bizkaia \\
\hline & $12 / 10$ & Una mujer de 53 años asesinada en Donostia & Gipuzkoa \\
\hline \multicolumn{4}{|c|}{ Fuente: Elaboración propia } \\
\hline
\end{tabular}




\section{Anexo 2}

Modelo de ficha utilizado para el vaciado de los diarios

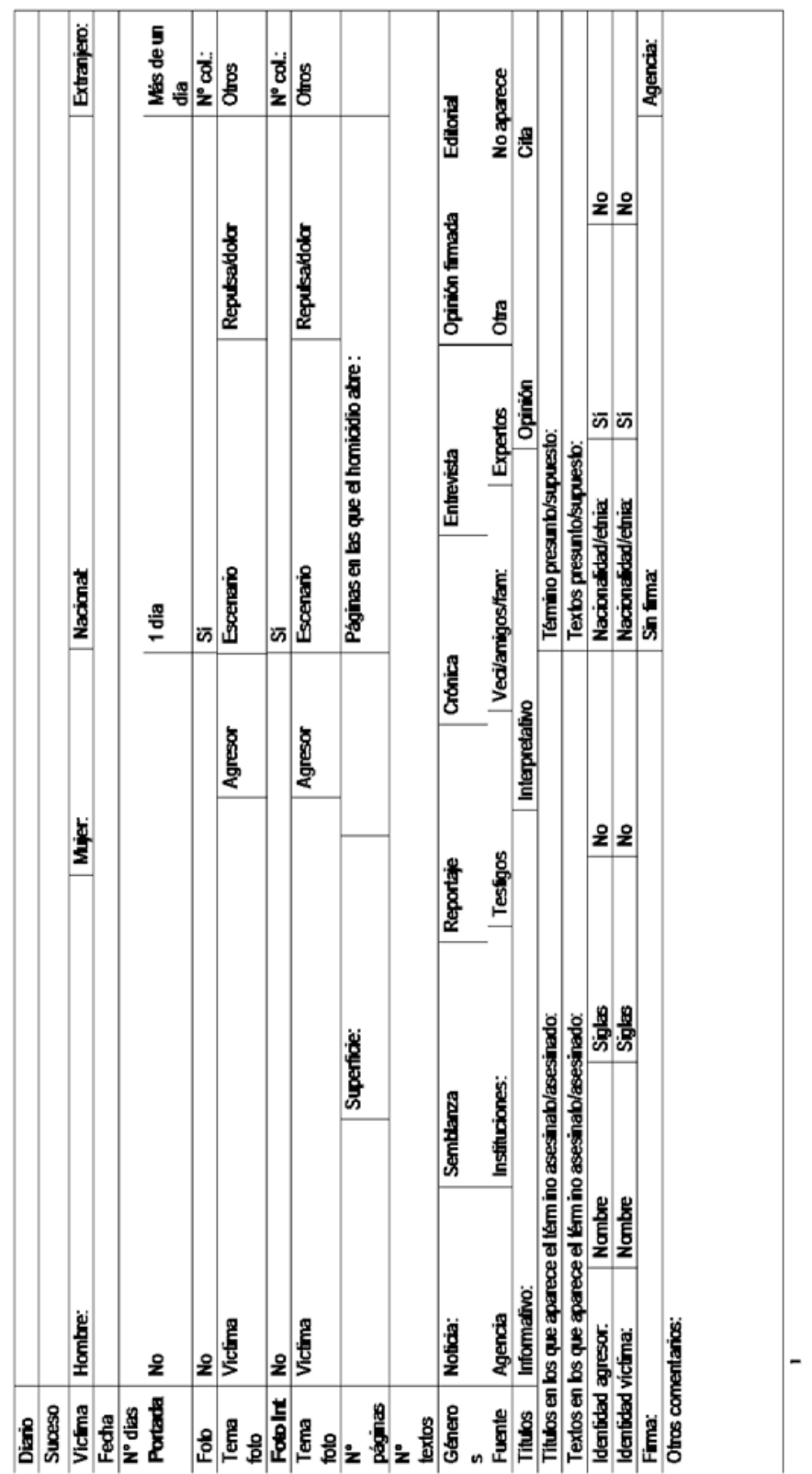

Fuente: Elaboración propia 